\title{
BOLTON TOOTH-SIZE DISCREPANCIES AMONG UNIVERSITY OF MALAYA'S DENTAL STUDENTS
}

S.A. Othman, H. Mookin, M.A. Asbollah, N.A. Hashim. Bolton tooth-size discrepancies among University of Malaya's dental students. Annal Dent Univ Malaya 2008; 15(1): 40-47.

\section{ABSTRACT}

The objective of this retrospective study was to investigate what percentage of the dental students in the University of Malaya has a tooth size discrepancy. The sample comprised 40 good quality pre-treatment study models with fully erupted and complete permanent dentitions from first molar to first molar, which were selected from the dental students of the University of Malaya. The mesiodistal diameter tooth sizes were randomly measured manually from first molar to first molar using digital calliper (Mitutoyu) accurate to 0.01 $\mathrm{mm}$, and the Bolton analyses for anterior and overall ratios were calculated by scientific calculator. Reproducibility analysis for intra- and interexaminer calibrations was assessed by measuring 10 study models twice, a week apart. A paired sample $t$-test and the correlation coefficient were used to evaluate the systematic and random errors of the measurements using Statistical Package for Social Sciences (SPSS) version 12.0. The reproducibility of the intra and inter-examiners for the sum of upper and lower mesiodistal tooth size were high (average mean difference $=0.62, r=0.82$ ). This study found $47.5 \%$ of the samples had anterior, and about $10 \%$ had overall tooth width ratios greater than 2 standard deviations from Bolton's mean. Large percentage of the dental students of the University of Malaya has tooth size discrepancies outside of Bolton 2 standard deviations. It would seem prudent to routinely perform the tooth size analysis and include the findings into orthodontic treatment planning.

Key words: Bolton tooth-size discrepancy, Bolton's ratios, tooth-size discrepancy

\section{INTRODUCTION}

A tooth-size discrepancy (TSD) conventionally has been described as a relative excess of tooth structure in one arch in relation to the other arch (1). It also can be defined as a disproportion among the size of individual teeth (2). For proper alignment and to achieve a good occlusal interdigitation of the dentition, the tooth size must be in harmony with the arch size. Although the natural teeth match very
Original Article

S.A. Othman ${ }^{1}$, H. Mookin ${ }^{2}$,
M.A. Asbollah ${ }^{2}$, N.A. Hashim

${ }^{1}$ Lecturer
Department of Children's Dentistry and
Orthodontics
Faculty of Dentistry
University of Malaya
50603 Kuala Lumpur
Telephone : 79674541
Email: sitiadibah(a,um.edu.my
2 Dental Officer, Ministry of Health
3 Private Orthodontist
Corresponding author: Siti Adibah Othman

well in most dentitions, approximately 5\% of population has some degree of discrepancy among the size of individual teeth (2).

The first investigation of mesio-distal width was studied by G.V Black (3) in 1902. He measured a large number of human teeth and from these measurements he set up tables of mean figures, which are still used as important references today. Several different investigators had followed Black's investigation with modification (4 - 7).

The best-known study of tooth size disharmony in relation to treatment of malocclusion was done by Bolton in 1958 (8). He developed a method of analyzing mesio-distal tooth size ratio between maxillary and mandibular teeth by evaluated 55 cases with excellent occlusions. The greatest mesiodistal diameter of all the teeth on each case was measured excepting the second and third molars. Two ratios were developed; anterior ratio $(77.2 \pm$ $1.65 \%$ ) which were obtained by measuring the six anterior teeth, and overall ratio $(91.3 \pm 1.91 \%)$ which were obtained by measuring from first molar to first molar. The formulas derived by Bolton are as follow:

$$
\text { Total ratio }(\%)=\frac{\text { sum mandibular ' } 12 '}{\text { sum maxillary ' } 12 \text { ' }} \times 100
$$

$$
\text { Anterior ratio }(\%)=\frac{\text { sum mandibular ' } 6 \text { ' }}{\text { sum maxillary ' } 6 \text { ' }} \times 100
$$

The data from this sample was then used to indicate the distance from the ideal of any measured ratio 
and thus the size of the discrepancy. He concluded that it would be difficult for proper occlusal interdigitation or coordination of arches in the finishing stage of orthodontic treatment without proper mesio-distal tooth size ratio between maxillary and mandibular teeth. Stiffer (9) replicated Bolton study in Class I occlusion and reported similar result. He concluded that the percentage of lower to upper anterior tooth size is a significant factor when attempting to harmonize tooth material.

In 1962, Bolton (10) had expanded his study on the clinical application of his tooth size analysis. He proposed a different overall ratio for premolar extraction cases. Patients, in whom no TSD existed after the extraction of four premolars, would have an overall ratio that fell in a range from $87 \%$ to $89 \%$ with the mean value of $88 \%$.

The prevalence of significant TSD is different for different population. Many studies have been carried out in various countries to determine the prevalence of the TSD in their populations $(18-21)$. This is may be due to the fact that orthodontists have realized the importance of this subject. However, Othman and Harradine (11) in their review paper on TSD and Bolton's ratios concluded that the prevalence of significant TSD in United Kingdom population of orthodontic patients remains uncertain, as is also the case for other population. To date, no study has been done on Malaysian population on the TSD and Bolton's ratio. Therefore, the aim and objective of this study is to investigate what percentage of the dental students in the University of Malaya has a TSD.

\section{MATERIALS AND METHODS}

Study casts of 40 dental students of the University of Malaya were used in this study. In the samples, 12 were males and 28 were females. All students were Malaysians between ages of $21-26$ years old, and they were in clinical year 3, 4 and 5 . None of the subjects had undergone orthodontic treatment. In this study the classifications of the malocclusion were not differentiated, hence the final sample consisted of different malocclusions.

The following inclusion criteria were used in the selection of the study models;

1) Good quality study models.

2) All permanent teeth were fully erupted and present from right first permanent molar to the left first permanent molar.

3) No extraction or interproximal stripping performed.

4) No obvious interproximal or occlusal wear of teeth.
The following were the exclusion criteria:

1) Broken study models.

2) Gross restorations, build-ups, crowns, onlays, class II amalgam or composite restoration that affect the tooth's mesiodistal diameter.

3) Congenitally missing teeth and impacted teeth and gross carious.

4) Gross carious teeth with involve mesial or distal surfaces.

All the study models were numbered and labeled according to the races and gender.

The samples were selected randomly for measurement using a website from http://www. randomization.com in A Random Permutation section. Measurement was made directly on the study models by using the electronic digital calipers (Digimatic Caliper, Mitutoyu) accurate to $0.01 \mathrm{~mm}$ with fine tips to improve the access into the interproximal distance. The width of each tooth was measured from its mesial contact point to its distal contact point at its greatest interproximal distance from first molar to first molar, with the caliper tips held perpendicular to the long axis of each tooth. Contact points were defined at the points on the approximate surfaces, as observed or estimated as those, which should be touching when the teeth were perfectly aligned (12).

Each sample was measured by the 2 operators (MAA and HM), and the average value was recorded. Only 8 to 10 models were measured each day to prevent any effects of fatigue (13). All the measurements for each tooth from first molar to first molar were then transferred to the data sheets. The sum of the total maxilla and the mandibular teeth (6 to 6) and sum of the anterior maxilla and mandibular teeth ( 3 to 3 ) were calculated using Microsoft excel program. The total and anterior ratios were determined by Bolton's formula (8):

$$
\text { Total ratio }(\%)=\frac{\text { sum mandibular ' } 12 \text { ' }}{\text { sum maxillary ' } 12 \text { ' }} \times 100
$$

$$
\text { Anterior ratio }(\%)=\frac{\text { sum mandibular ' } 6 \text { ' }}{\text { sum maxillary ' } 6 \text { ' }} \times 100
$$

Bolton's ratios were used as guidance in this research.

\section{Assessment of Reproducibility}

Each investigator (MAA and HM) was tested for their intra-examiner reproducibility of the method of measurement. Each of them measured 10 study casts twice which were randomly selected from 
the main study group, with a week between the measurements. The measurements were also tested for inter-examiner reproducibility.

\section{Statistical Analysis}

After the measurements corresponding to the sum of mesiodistal widths for the 6 maxillary and mandibular anterior teeth and the 12 maxiliary and mandibular teeth were obtained, their distribution was evaluated; and all the data were demonstrated to come from a normally distributed population. Kappa statistic (k) was used to measure level of agreement of the measurement between the 2 investigators. For assessment of the systematic error, the mean difference between the repeated measurements was used. The random error was assessed by using the standard deviation of the difference.

To determine whether there were gender differences in the incidence of the tooth-size ratios and discrepancies, an independent-sample $t$-test was performed. Statistical analyses were carried out using Statistical Package for Social Sciences (SPSS) version 12.0.

\section{RESULTS}

\section{Reproducibility}

The intra-examiner systematic and random errors for both examiners is detailed in table 1a (HM) and $1 \mathrm{~b}$ (MAA). There was no significant difference found between the two sets of measurements. The correlation coefficient for all descriptive was relatively high for both examiners.

Table 2 contains the analysis of systematic and random errors between 2 examiners. There was no significant difference found between the 2 examiners and the correlation coefficient was also relatively high for all descriptive.

\section{Gender Distribution}

Table 3 summarizes the mean for male and female, mean differences and statistical comparisons of the tooth size ratios. It shows that there is no significant sexual dimorphism for any of the parameters; hence the sexes were combined for all other analyses.

\section{Size and Distribution of Tooth Size Discrepancy}

Figure 1a shows the distribution of anterior tooth-width ratios in this study categorized by Bolton's original means and standard deviations. This format will show the percentage of subjects falling more than 2 standard deviations from Bolton's mean. $47.5 \%$ of the sample had anterior tooth-width ratios greater than 2 standard deviation from Bolton's mean $(32.5 \%$ greater than +2 standard deviation and $15 \%$ greater than -2 standard
Table 1a. Intra-examiner reproducibility (systematic and random errors). Observer HM. Mean difference,

$P$ value, SD and correlation

\begin{tabular}{lcccc}
\hline Descriptive & $\begin{array}{c}\text { Mean } \\
\text { difference }\end{array}$ & $P$ value & $\begin{array}{c}\text { SD of } \\
\text { differences }\end{array}$ & Correlation \\
\hline $\begin{array}{l}\text { Upper sum } \\
\text { (anterior) }\end{array}$ & -0.124 & .794 & 1.454 & 0.791 \\
$\begin{array}{l}\text { Lower sum } \\
\text { (anterior) }\end{array}$ & 0.323 & .254 & 0.838 & 0.944 \\
$\begin{array}{l}\text { Upper sum } \\
\text { (overall) }\end{array}$ & 0.284 & .671 & 2.046 & 0.815 \\
$\begin{array}{l}\text { Lower sum } \\
\text { (overall) }\end{array}$ & 1.057 & .314 & 3.137 & 0.815 \\
\hline$n=10 . \quad P<0.05$ & & & \\
\hline \multicolumn{1}{c}{$\quad P$} & & & \\
\hline
\end{tabular}

Table 1b. Intra-examiner reproducibility (systematic and random errors). Observer MAA. Mean difference, $P$ value, SD and correlation

\begin{tabular}{lcccc}
\hline Descriptive & $\begin{array}{c}\text { Mean } \\
\text { difference }\end{array}$ & $P$ value & $\begin{array}{c}\text { SD of } \\
\text { differences }\end{array}$ & Correlation \\
\hline $\begin{array}{l}\text { Upper sum } \\
\text { (anterior) }\end{array}$ & 0.662 & .479 & 2.836 & 0.603 \\
$\begin{array}{l}\text { Lower sum } \\
\text { (anterior) }\end{array}$ & 0.439 & .218 & 1.049 & 0.755 \\
$\begin{array}{l}\text { Upper sum } \\
\text { (overall) }\end{array}$ & 0.416 & .658 & 2.870 & 0.793 \\
$\begin{array}{l}\text { Lower sum } \\
\text { (overall) }\end{array}$ & 0.943 & .154 & 1.197 & 0.859 \\
\hline
\end{tabular}

$n=10 . \quad P<0.05$

Table 2. Inter-examiner reproducibility (systematic and random errors). Observer HM and MAA. Mean difference, $P$ value, SD and correlation

\begin{tabular}{lcccc}
\hline Descriptive & $\begin{array}{c}\text { Mean } \\
\text { difference }\end{array}$ & $P$ value & $\begin{array}{c}\text { SD of } \\
\text { differences }\end{array}$ & Correlation \\
\hline $\begin{array}{l}\text { Upper sum } \\
\text { (anterior) }\end{array}$ & -1.334 & .054 & 1.390 & 0.821 \\
$\begin{array}{l}\text { Lower sum } \\
\text { (anterior) }\end{array}$ & -0.966 & .060 & 0.856 & 0.901 \\
$\begin{array}{l}\text { Upper sum } \\
\text { (overall) }\end{array}$ & 0.598 & .321 & 1.800 & 0.867 \\
$\begin{array}{l}\text { Lower sum } \\
\text { (overall) }\end{array}$ & 0.335 & .743 & 3.133 & 0.851 \\
\hline $\begin{array}{l}n=10 . \\
n<0.05\end{array}$ & & & & \\
\hline
\end{tabular}

Table 3. Descriptive Comparison of Anterior Ratio and Overall Ratio for Male and Female. Mean, mean differences and $P$ value

\begin{tabular}{lcccc}
\hline Descriptive & Female & Male & $\begin{array}{c}\text { Mean } \\
\text { difference }\end{array}$ & P value \\
\hline & Mean & Mean & & \\
Anterior ratio (\%) & 78.73 & 75.83 & 2.90 & 0.036 \\
Overall ratio (\%) & 91.75 & 90.85 & 0.91 & 0.411 \\
\hline
\end{tabular}

*Significant $P<0.01$ 
deviation). Figure $1 \mathrm{~b}$ shows the same data for the overall ratio. For the overall ratio, the percentage falling more than 2 standard deviations from Bolton's mean was $10 \%$ of the sample $(2.5 \%$ greater than +2 standard deviation and $7.5 \%$ greater than -2 standard deviation).

\section{DISCUSSION}

\section{Sample}

In this study, only 40 study models were selected among dental students of University of Malaya to be used as a sample size. The sample size was relatively small compared to other studies, where larger sample sizes (usually more than 50) were used. This was because due to the difficulties encountered when collecting the sample. Not all of the dental students in the Dental Faculty, University of Malaya have their own study model, and some of them have lost their models. Even though initially quite a number of study models were collected, unfortunately only 40 study models followed the inclusion criteria. Many of the study models were not suitable because the quality were not satisfactory. Longer time was needed to collect a good quality and bigger sample size. Due to the limited elective project's time frame, we felt that 40 study models were sufficient for this study as this study only represent the dental student's population in the Dental Faculty, University of Malaya.

The samples were collected without analysis according to the malocclusion groups and also the racial groups. Only the sex different was determined according to the Bolton anterior and overall ratios. The racial comparisons were excluded in this study because of the small sample size of Indian students who are the minority $(n=1)$. In view of this limitation in sample size and variables, the significance of the analyzed data may not be the true reflection.

\section{Reproducibility}

In every study that involves measuring, reproducibility evaluation is very important in order to determine the error of measurement. Houston (14) quoted that if any study using measurements is to be of value, it is imperative that such an analysis be undertaken and reported. Ten study models were randomly selected form the main sample to assess the reproducibility of the measurements. Table 1a and $1 \mathrm{~b}$ list the intra-examiner systematic and random errors results of 2 set of measurements for HM and MAA performed on the same study model twice by the same examiner with the measurements separated by a 1 -week time interval. A paired sample $t$-test and the correlation coefficient were used to evaluate the systematic and random errors between the two measurements of the sum for upper and lower mesiodistal tooth sizes. The mean differences were small for HM and also for MAA, and the P values showed no significant differences between the means. The standard deviation of differences for HM and MAA were slightly high, and this shows that the random errors for both examiners were higher compared to the systematic error. However, the correlation coefficient for both examiners was relatively high; it can be assumed that the random error was within the acceptable limit.

Inter-examiner systematic and random errors were also evaluated by both examiners. Table 2 shows no significant systematic differences in the mean measurements obtained by the 2 examiners, and the mean differences were also small. Correlation coefficient for all descriptive was also relatively high. In conclusion, the reproducibility of the intra and inter-examiners for the sum of upper and lower mesiodistal tooth sizes were relatively high (average mean difference $=0.62, r=0.82$ ).

\section{Method of Measurement}

Previous studies $(2,15,16)$ had reported the advantages of using the computerized method for calculating Bolton tooth-size analysis, where a digital calliper can be linked to computers for quick calculation of the anterior and posterior ratios. In this study, a digital calliper was used to measure the mesiodistal tooth width of the samples. However the sum of the upper and the lower mesiodistal tooth width and the calculation of the anterior and overall Bolton's ratios were calculated manually using Microsoft excel program. Microsoft excel program was used because the software for calculating Bolton tooth-size analysis was not available.

Paredes et al. (17) investigated the reproducibility of a new digital method versus the traditional one for measuring tooth sizes. The reproducibility of both methods was analyzed to determine the intra- and inter-examiner measurement errors. The results demonstrated that the digital method provided results comparable with those of the traditional technique, since the regression parameters for each index showed that the correlation coefficients of the two methods were very high and similar to each other. Similarly, the study done by Othman and Harradine (16), reported that the reproducibility of 2 methods of measurement between manual measurement using the Odontorule slide rule and the other employed digital calliper and the HATS analysis software were similar. The only advantages of the HATS method were it was much more rapid and inherently less prone to blunders. Present evidence shows that manual measurement is still suitable to be used in research performing Bolton tooth-size analysis. 
Size and Distribution of Tooth-size Discrepancy among University of Malaya's Dental Student

Originally, Bolton (8) suggested that a ratio greater than $1 \mathrm{SD}$ from his reported mean values indicated a need for diagnostic consideration. More recently, a clinically significant tooth-width ratio discrepancy has generally been defined as 2 standard deviations outside Bolton's published mean ratio (18 - 21). By using this definition, an anterior ratio below $73.9 \%$ or above $80.5 \%$ and a total ratio below $87.5 \%$ or above $95.1 \%$ would be considered clinically significant. In a normally distributed population, $5 \%$ of subjects would fall more than 2 standard deviations from the mean. The present study found $47.5 \%$ of the sample had anterior tooth width ratios greater than 2 standard deviations from Bolton's mean $(32.5 \%$ greater than +2 standard deviation and $15 \%$ greater than -2 standard deviation) (Figure 1). This result supports others $(18-23)$ which have found that a dental student population in the University of Malaya has a higher percentage of outliers than Bolton's sample.

Interestingly, when compare to normally distributed population (2), the present sample found almost double $(10 \%)$ of the population had total tooth-width ratios greater than 2 standard deviations from Bolton's mean $(2.5 \%$ more than +2 standard deviation and $7.5 \%$ greater than -2 standard deviation) (Figure 2). Table 4 contains the percentage of significant discrepancies by this definition found in various studies.

It can be seen that for the anterior ratio, the figure from the current study was almost two times higher than those reported by Crosby and Alexander (18), Freeman et al. (19), Santoro et al. (20), Araujo and Souki (22) and Bernab et al. (21); and almost three times higher than reported by Othman and Harradine (23). The overall ratio figure from the present study coincided with those presented by Freeman et al. (19) and Santoro et al. (20), and was lower by half of that reported by Bernab et al. (21) and Othman and Harradine (23). It is also clear from the table 4 that all studies have found a lower percentage of cases falling outside Bolton's standard deviations for the overall ratio than for the anterior ratio.

It can also be seen that the anterior discrepancy was greater in mandibular excess than maxillary excess, whereas the overall discrepancy was greater in maxillary excess than mandibular excess. The finding for the anterior ratio is similar to those reported by Freeman et al. (19). In their retrospective study of 157 patient records, they reported that $30.6 \%$ of patients had anterior ratios outside 2 standard deviations from Bolton's mean, and 13.4\% had total ratios greater than 2 standard deviations from Bolton's mean values. They stated that the overall discrepancy was equally likely to be an excess

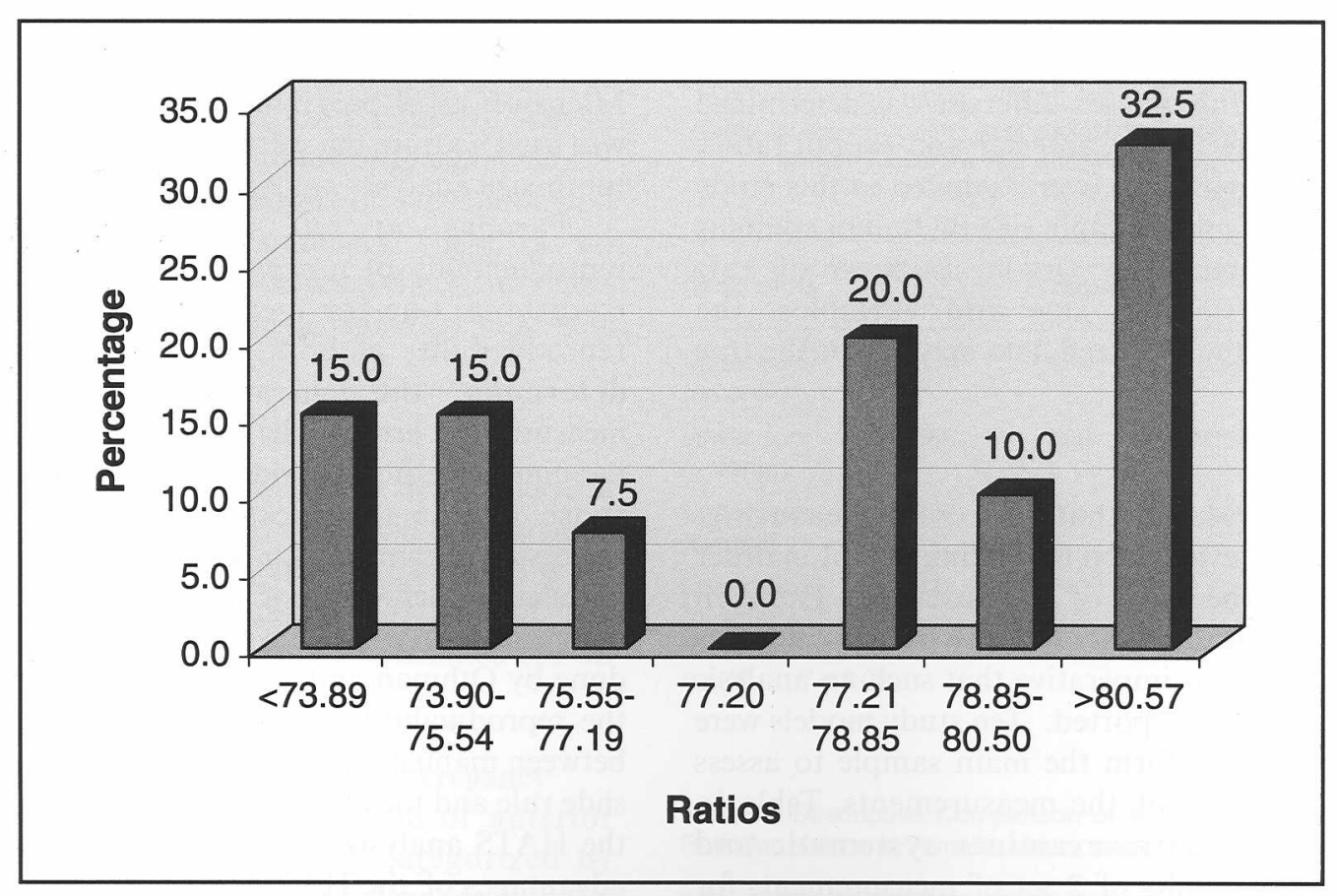

77.20 is Bolton mean

$75.55-77.19 \& 77.21-78.85$ within $1 S D$

$73.90-75.54 \& 78.86-80.50$ within $1 S D \& 2 S D$

$<73.89 \&>80.15$ within $2 S D$

Figure 1: Anterior Bolton ratios: the distribution (percentage) of subjects in this study categorized by the standard deviations of Bolton's original study. 


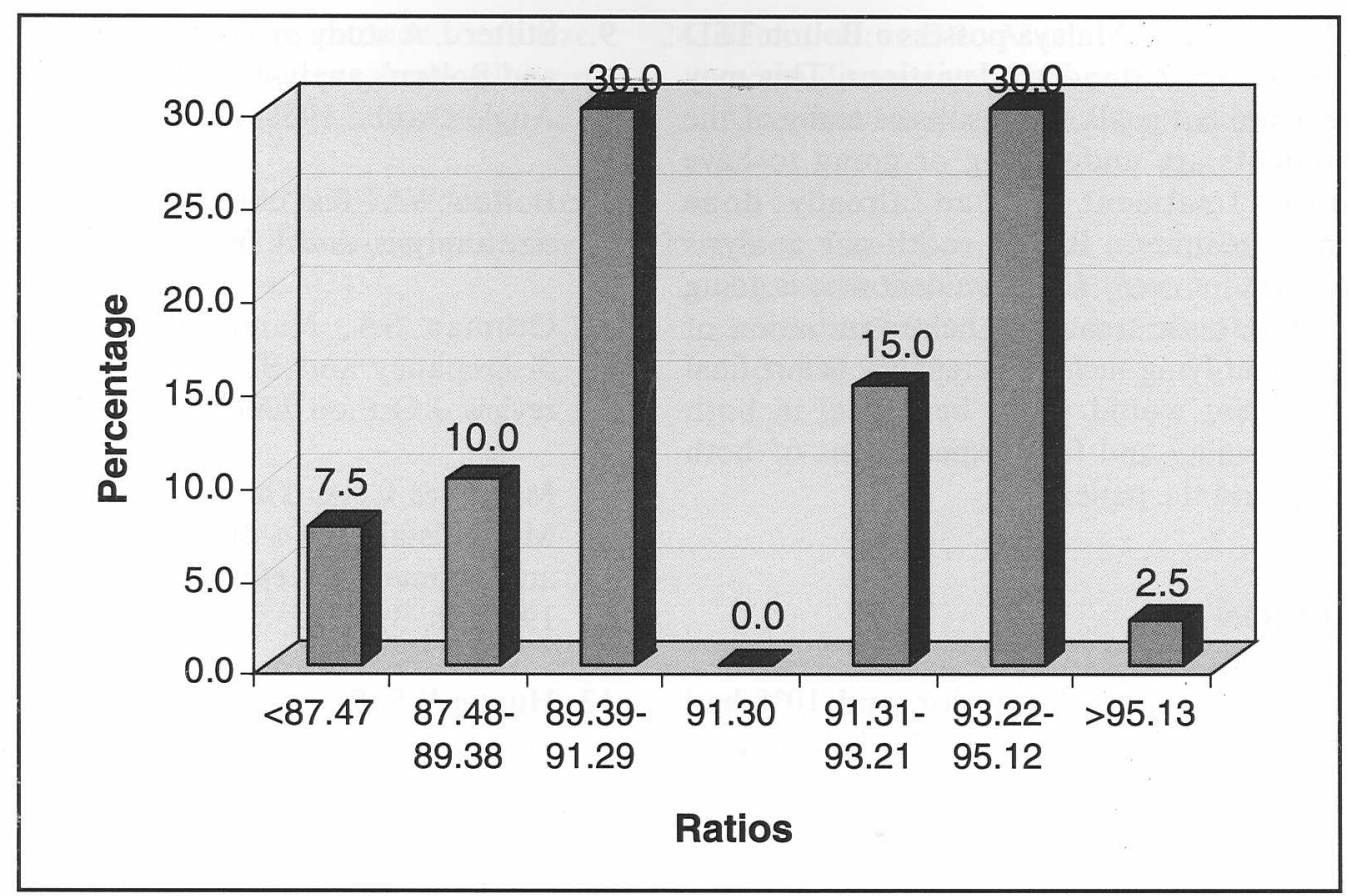

91.30 is Bolton mean

89.39-91.29\& 91.31-93.21 within $1 S D$

87.48-89.38\& 93.22-95.12 within $1 S D \& 2 S D$

$<87.47 \&>95.13$ within $2 S D$

Figure 2: Overall Bolton ratios: The distribution (percentage) of subjects in this study categorized by the standard deviations of Bolton's original study.

Table 4. Percentage of potential patients with 'substantial' Bolton discrepancies (more than 2 SDs from the mean ratios in Bolton's original study) from previous studies and the present study

\begin{tabular}{lcc}
\hline & $\begin{array}{c}\text { Anterior ratio } \\
(\%)\end{array}$ & $\begin{array}{c}\text { Overall ratio } \\
(\%)\end{array}$ \\
\hline Crosby and Alexander (18) & 22.9 & - \\
Freeman et al. (19) & 30.6 & 13.5 \\
Santoro et al. (20) & 28.0 & 11.0 \\
Araujo and Souki (22) & 22.7 & - \\
Bernabé et al. (21) & 20.5 & 5.0 \\
Othman and Harradine (23) & 17.4 & 5.4 \\
Present study & 47.5 & 10.0 \\
\hline
\end{tabular}

in the maxilla or the mandible, whereas the anterior discrepancy was nearly twice as likely to be a mandibular excess $(19.7 \%)$ than a maxillary excess $(10.8 \%)$.

An important source of variation in results for these studies may, of course, be variations in the composition and selection of the samples. Previous studies done by Richardson and Malhotra (24), Nie and Lin (25), Araujo and Souki (22), and Othman and Harradine (23) had suggested that the gender difference was not significant and this study supported that view (Table 3). Racial grouping however, might be a source of variation. In the present study, racial group was not specified in the sample. Malaysian population consist many races, and it would be wise to separate or categories the racial groups as different races may have their own ratios. However in this present study investigation on TSD in the Malaysian population were not intended due to time constrain. Hence the samples were limited to the dental students in the University of Malaya. Crosby and Alexander (18), in their mixed gender sample of 109 orthodontically treated patients with various malocclusions, also did not specify the racial group used in their sample. The sample from study done by Othman and Harradine (23) was entirely from Caucasian ethnicity. $17.4 \%$ of the sample had anterior, and $5.4 \%$ had overall ratios greater than 2 standard deviations from Bolton's mean. These figures are lower than the present study.

The sample selection process among students in Dental Faculty of University Malaya perhaps may explain the different finding observed from the present study. Some of the samples were those with severe malocclusion. It is also possible the dental students were diverse in racial background. Thus, it would seem logical that the percentage of dental students with significant discrepancies may be somewhat dependent on the selection process and the characteristics of the population among dental students.

The findings from the present study suggest that a large number of dental students in the Dental 
Faculty, University of Malaya possess a Bolton TSD outside of Bolton 2 standard deviations. This may influence treatment goals and results as many of the dental students are undergoing or going to have orthodontic treatment or had already done orthodontic treatment. Bolton tooth-size analysis should be used for every dental student who is going to have orthodontic treatment before initiation of treatment. Identifying such a discrepancy before final tooth alignment would prove beneficial in both treatment planning and final expectations of both the clinician and the patient.

\section{CONCLUSION}

$47.5 \%$ of the sample had anterior, and $10 \%$ had overall ratios greater than 2 standard deviations from Bolton's mean. These figures indicate that high percentage of the dental students of the University of Malaya has TSD outside of Bolton 2 standard deviations. It would seem prudent to routinely perform the tooth-size analysis and include the finding into orthodontic treatment planning.

\section{REFERENCES}

1. Fields H. Orthodontic restorative treatment for relative mandibular anterior excess size problems. Am J Orthod 1981; 79: 176-183.

2. Proffit WR. Contemporary orthodontics, $3^{\text {rd }}$ edn. St. Louis 2000: 170.

3. Black GV. Descriptive anatomy of human teeth, $4^{\text {th }}$ edn. S.S. White: Philadelphia, 1902.

4. Ballard ML. Asymmetry in tooth sizes a factor in the etiology, diagnosis and treatment of malocclusion. Angle Orthod 1944; 14: 67-71.

5. Neff $\mathbf{C W}$. Tailored occlusion with the anterior coefficient. Am J Orthod 1949; 35: 309-314.

6. Steadman SR. The relationship of upper anterior teeth to lower anterior teeth as present on plaster models of a group of acceptable occlusion. Angle Orthod 1952; 22: 91-97.

7. Lundström A. Intermaxillary tooth width ratio and tooth alignment and occlusion. Acta Odontol Scan 1954; 12: 265-292.

8. Bolton WA. Disharmony in tooth size and its relation to the analysis and treatment of malocclusion. Angle Orthod 1958; 28: 113-130.
9. Stifter J. A study of Pont's, Howes', Rees', Neff's and Bolton's analyses on Class I adult dentitions. Angle Orthod 1958; 28: 215-225.

10. Bolton WA. The clinical application of toothsize analysis. Am J Orthod 1962; 48: 504-529.

11. Othman SA, Harradine NWT. Tooth-size discrepancy and Bolton's Ratios: a literature review. J Orthod 2006; 33: 45-51.

12. Moorrees CFA, Thomsen SO, Jensen E, et al. Mesiodistal crown diameters of the deciduous and permanent teeth in individuals. J Dent Res 1957; 36: 39-47.

13. Hunter WS, Priest WR. Errors and discrepancies in measurement of tooth size. J Dent Res 1960; 39: 405-514.

14. Houston WJB. The analysis of errors in orthodontic measurements Am J Orthod 1983; 83: 382-390.

15. Tomassetti JJ, Taloumis LJ, Denny JM, et al. A comparison of 3 computerized Bolton tooth-size analyses with a commonly used method. Angle Orthod 2001; 71: 351-357.

16. Othman SA, Harradine NWT. Tooth-size discrepancy and Bolton's ratios: the reproducibility and speed of two methods of measurement. J Orthod 2007;34: 232-240.

17. Paredes V, Gandia JL. A new, accurate and fast digital method to predict unerupted tooth size. Angle Orthod 2005; 76: 14-19.

18. Crosby DR, Alexander CG. The occurrence of tooth size discrepancies among different malocclusion groups. Am J Orthod Dentofacial Orthop 1989; 95: 457-461.

19. Freeman JE, Maskeroni AJ, Lorton L. Frequency of Bolton tooth size discrepancies among orthodontic patients. Am J Orthod Dentofacial Orthop 1996; 110: 24-27.

20. Santoro M, Ayoub ME, Pardi VA et al. Mesiodistal crown dimensions and tooth size discrepancy of the permanent dentition of Dominican Americans. Angle Orthod 2000; 70: 303-307.

21. Bernab E, Major PW, Flores-Mir C. tooth-width ratio discrepancies in a sample of Peruvian adolescents. Am J Orthod Dentofacial Orthop 2004; 125: 361-365. 
22. Araujo E, Souki M. Bolton anterior tooth size discrepancies among different malocclusion groups. Angle Orthod 2003; 73: 307-313.

23. Othman SA, Harradine NWT. Tooth size discrepancies in an orthodontic population. Angle Orthod 2007; 77: 668-674.
24. Richardson ER, Malhotra SK. Mesiodistal crown dimension of the permanent dentition of American Negroes. AM J Orthod 1975; 68: 157164.

25. Nie Q, Lin J. Comparison of maxillary tooth size discrepancies among different malocclusion groups. AM J Orthod Dentofacial Orthop 1999; 116: $539-544$. 